Article

\title{
Designing a Model for Facilitating the Inclusion of Higher Education International Students with Disabilities in South Africa
}

\author{
Nina $(\mathrm{HG})$ du Toit \\ Department of Research, Innovation and Partnerships, Faculty of Informatics and Design, Cape Peninsula University of \\ Technology, 7535 Cape Town, South Africa; E-Mail: ninadutoit1@gmail.com
}

Submitted: 30 June 2018 | Accepted 10 August 2018 | Published: 6 December 2018

\begin{abstract}
Higher education in South Africa is regulated by several policies, and the obligation of increased access and participation of persons with disabilities into higher education is recognized in legislation (Department of Education, 1997; Department of Higher Education and Training, 2013). However, research indicates that the proportion of students with disabilities in higher education and in study programmes abroad is still very low worldwide (Fazekas, 2017; Organisation for Economic Co-operation and Development, 2011). Study opportunities for these students in higher education institutions abroad, including South Africa, should therefore be increased to provide equal access and experience in an inclusive higher education environment. This study explores possible reasons for the low engagement of South African students with disabilities in international mobility programmes and the function of key role-players in supporting international students with disabilities studying in South Africa (incoming students) and South African students with disabilities studying abroad (outgoing students). This study also explores the ways by which the exchange process could be facilitated more effectively within the context of an inclusive higher education environment. Data on the support services offered to these students was obtained by means of questionnaires sent to the International Relations Offices and Disability Rights Units at higher education institutions in South Africa. The study culminated in the design of a model which specifies the roles of the various role-players in supporting international students with disabilities during their pre-departure, study and return phases.
\end{abstract}

\section{Keywords}

disability; higher education; international mobility programme; South Africa; student

\section{Issue}

This article is part of the issue "Students with Disabilities in Higher Education", edited by Geert Van Hove (Ghent University, Belgium/VU Amsterdam, The Netherlands), Minne Bakker (VU Amsterdam, The Netherlands) and Alice Schippers (Disability Studies in the Netherlands/VU Amsterdam, The Netherlands).

(C) 2018 by the author; licensee Cogitatio (Lisbon, Portugal). This article is licensed under a Creative Commons Attribution 4.0 International License (CC BY).

\section{Introduction}

During the last century, a considerable amount of education-related research focused on the influence of globalisation and internationalisation on the character and behaviour of higher education institutions (Altbach, 2002; Cross, Mhlanga, \& Ojo, 2011; De Wit, 2011; Edwards, 2007; International Association of Universities [IAU], 2012; International Education Association of South Africa, 2014; Mavhungu, 2003; McLellan, 2008; Mitchell \& Nielsen, 2012; Oxford University, 2017; Tadaki, 2013). This contributed to the increased focus on the internationalisation of higher education. Knight (2004, 2013) emphasises that internationalisation needs to be understood at the national as well as at the institutional level. She defines internationalisation of higher education as "the process of integrating an international, intercultural or global dimension into the purpose, functions or delivery of postsecondary education" (Knight, 2004, p. 11). This definition includes the teaching, research and service elements of an institution. Egron-Polak and Hudson (2014) emphasise that the internationalisation of higher education could be a central motor and integral part of an ongoing process of change. Waters (2009) also points out that institutions often borrow cross-national and international policies from each other. These poli- 
cies are mostly linked to international political organisations, such as the European Union, World Bank and the United Nations Educational, Scientific and Cultural Organisation ([UNESCO], 2017).

The literature further indicates that higher education institutions could play a distinctive role in the internationalisation of higher education (De Wit, 2011; Lutabingwa, 2005; Mthembu, 2004). According to Van de Water, Green and Koch (2008) this could be done through different kinds of international collaborations and strategic partnerships such as the well-known European Union's Erasmus Mundus projects. Institutional strategic partnerships are mostly long-term, comprehensive collaborations between two or more institutions, based on principles of sustained reciprocity and mutual benefit.

At the institutional level, higher education institutions have developed their own strategies to internationalise their research and teaching. The IAU's 4th global survey $(2014)^{1}$ on internationalisation of higher education provides important information regarding these developments, together with challenges in internationalisation of higher education (Egron-Polak \& Hudson, 2014). According to the IAU's Report, student learning and mobility could be one of the priorities of internationalisation, with the expected benefit of student knowledge and appreciation of international issues. The recruiting of all students, including students with disabilities, to participate in international mobility programmes ${ }^{2}$ should, therefore, be one of the focus areas at higher education institutions.

In South Africa, several policies have been developed in recent years that regulate higher education in alignment with international developments. This includes the Education White Paper 3 (Department of Education, 1997) and the White Paper on Post-School Education and Training (Department of Higher Education and Training [DHET], 2013). Values such as equity, nondiscrimination, and humanity, which highlight the principle of social inclusion, are endorsed by the Constitution of the Republic of South Africa (1996). Regarding higher education, these policies promote increased access for previously disadvantaged students ${ }^{3}$, including students with disabilities. As articulated in the National Plan for Higher Education (Department of Higher Education, 2001), the moral and educational responsibility rests with individual institutions to ensure effective access and success for all students.
However, higher education access and participation for students with disabilities should be broadened to include international exposure and experience in an inclusive environment, as well as the development of a student network of international partners. To achieve this, UNESCO (2017) stipulates that successful implementation of inclusion principles depends on an integrated working system, involving all role-players.

No national data or other information could be found regarding incoming and outgoing international students with disabilities ${ }^{4}$ at higher education institutions in South Africa, although several policies and reports have already emphasised the need for a more comprehensive databank regarding students with disabilities in higher education (Department of Social Development, 2015; Howell, 2005). However, MacGregor (2014, p. 1) points out that "since 2007, the average growth rate of all international students has been $4.4 \%$ per annum, compared to the national average of $5.47 \%$ ". Under these circumstances, the increase of numbers of all international students necessitates the need for identifying key role-players at higher education institutions to ensure that all international students benefit optimally from their international experience.

Rouhani (2007) distinguishes several key role-players in the broader framework of the internationalisation of higher education. These include international agencies, national governments, higher education institutions, staff, students, and the private sector. The aims of these key role-players may differ, overlap or complement each other. In the South African context, key roleplayers include government departments, the higher education sector, institutions, statutory bodies, professional associations, students and sponsors. According to Rouhani (2007) the interactions among the above key role-players lack coordination. ${ }^{5}$ Rouhani (2007) also points out that no national policy on internationalisation in South African higher education has been finalised yet. However, on 8 May 2017, the DHET released a draft policy framework for the internationalisation of higher education for comment.

\section{Access to International Higher Education Mobility Programmes for Students with Disabilities}

As a human rights and development issue, disability is not an attribute of a person, but results from "the inter-

\footnotetext{
${ }^{1}$ This report presents the largest and the most geographically comprehensive collection of primary data on internationalisation of higher education available today.

2 In this study the term "mobility" refers to students who study abroad without a partnership or agreement between his/her home institution and a host institution. Most of these students register for a full degree at the host institution. The term "exchange" applies to Erasmus Mundus scholarships which runs from a minimum of one month to a maximum of one year. An exchange student lives temporarily in a foreign country and attends courses at a host institution but remains registered at his/her home institution. The host institution does not award degrees/diplomas to exchange students.

${ }^{3}$ The term "previously disadvantaged students" refers, amongst others, to "the difficulty experienced by disabled people in South Africa, especially disabled black people, who have been historically disadvantaged in a number of ways under the apartheid system, including substantial exclusion from all levels of education" (Howell, 2005, p. 18).

4 The term "incoming International students with disabilities" refers to students coming to South Africa from countries outside South Africa, whereas "outgoing international students with disabilities" refers to students from South Africa studying at a higher education institution abroad.

${ }^{5}$ Fazekas and Ho (2014, p. 54) also highlight the "lack of adequate information or insufficient cooperation within and between Higher Education Institutions when it comes to supporting international students with disabilities".
} 
action between persons with impairments and attitudinal and environmental barriers that hinder their full and effective participation in society on an equal basis with others" (United Nations, 2006, p. 3). The South African disability movement and government also approach disability from a social model perspective. Howell (2005, p. vi) states that "the response to disability in the social model is the restructuring of society for it to be able to deal appropriately with people with impairments". It also "enables people with disabilities to express their situation in terms of human rights and as an issue of equality" (Fazekas, 2017, p. 2).

According to the United Nations Convention on the Rights of Persons with Disabilities ([UNCRPD]; United Nations, 2006, p. 3), people with disabilities include "those who have long-term physical, mental, intellectual or sensory impairments which, in interaction with various barriers, may hinder their full and effective participation in society on an equal basis with other". ${ }^{6}$ In order to curb the potentially devastating effects of these barriers, the international community has introduced legislative interventions, including the UNCRPD (United Nations, 2006) and the World Health Organisation's World Report on Disability (2011), which seek to entrench the human rights of individuals with disabilities. The UNCRPD addresses a variety of issues, including the rights of all forms and levels of education (United Nations, 2006, Article 24). In higher education, this means access for students with disabilities to all opportunities, facilities and services that are available to other students, enhancing their full participation in various university activities and embracing the social model of disability (Broderick, 2018; Fazekas, 2017).

There is an extensive literature worldwide in the field of international mobility programmes in higher education (for e.g., Daly \& Barker, 2005; Dean \& Jendzurski, 2013; Mitchell \& Vandegrift, 2014), but limited information on international students with disabilities. However, the Association for Higher Education Access and Disability, the European Association on International Education: Access and Diversity Expert Community [EAIE: $A D E C]$, the European Commission, and the European Disability Forum are useful resources on matters concerning students with disabilities' international involvement, experiences, as well as learning and access needs. The Support Centre for Inclusive Higher Education (SIHO, \& LINK Network, 2012), as well as Fazekas and Ho (2014), and Fazekas (2017), undertook research projects on the international mobility of students with disabilities in European countries, whereas the European Action on Disability within Higher Education (2016) explored the mobility of all students in the light of diversity. In addition, Mitra (2006) developed a survey of daily routines of international students with disabilities, whereas Holben and Ozel (2015) focused on the mentoring of these students. The Erasmus Student Network in Europe ([ESN], 2017) recently finalised their research on the interna- tional experience of students with disabilities in international mobility programmes and launched their new MappED inclusive mobility platform in Brussels on 30 August 2017.

In 1995, with funding from the United States, Mobility International USA (MIUSA) launched the National Clearinghouse on Disability and Exchange to broaden the participation of people with disabilities in international exchange programs (MIUSA, 2017). MIUSA offers comprehensive information, referral services, and training for people with disabilities and exchange organisations (Brademas, Fulbright, \& Sygall, 1997). Several other organisations also provide information and services on the international mobility of students with disabilities. These include, amongst others, the American Higher Education Association for the Disabled, as well as Emerging Horison.

According to the European Commission (2014), only 339 students with disabilities participated in international mobility (study) programmes during the academic year 2012-2013. Although an increase of $15 \%$ has been observed in comparison with previous years, the percentage of students with disabilities who participate in these programmes is still exceptionally low (Fazekas, 2017; Institution of Higher Education, 2016). MIUSA (2017), as well as Dessoff (2006), also highlight the lack of participation and the under-representation of students with disabilities in international mobility programmes.

\section{Overview of the Study}

The study was guided by the following three research questions: a) What are the reasons for the low engagement of students with disabilities in international mobility programmes? b) Who are the key role-players in facilitating the exchange experience of international students with disabilities in an inclusive higher education environment? c) What are the roles and responsibilities of the key role-players in supporting international students with disabilities in meeting their learning and access needs effectively?

As contextual framework for exploring the interdependence and roles of relevant role-players in supporting international students with disabilities, the ecological system theory of Bronfenbrenner (1979; Skinner, 2012) was utilised in an adapted format. The theory includes micro-, meso-, exo-, macro- and chron-systems. These systems are linked and influence one another. In this study, the micro-systems include the institutional non-academic and academic staff, the student population, international students with disabilities, as well as several external roleplayers. In the adapted format, the meso-system represents the interactions between the micro-systems (different role-players) in an inclusive higher education environment. The exco-system represents the host/home institution with its internal policies on internationalisation. All these systems influence each other's functionality and

\footnotetext{
${ }^{6}$ In this study, the definition of people with disabilities also includes people with chronical illnesses.
} 
operate within the overall macro-system of international higher education. Finally, a support services model is proposed that stipulates the functions of the different roleplayers in supporting international students with disabilities, and also indicates other aspects involved in the social inclusion of these students.

The data collection tools consisted of documents and questionnaires. Since the main purpose of the data collection process was to identify current tendencies regarding the research topic at the respondents' higher education institutions, the captured data was not analysed quantitatively. Due to the small number of respondents ${ }^{7}$, the findings could not be generalised. Using the content analysis method, specific themes were identified. To ensure the validity and trustworthiness of the captured data, data was double-checked with the specific respondents.

Although South Africa has 26 public higher education institutions, only 22 of these complied with the selection criteria for respondents. ${ }^{8}$ For institutions who met the criteria, comprehensive questionnaires were developed for their IROs and DRUs, respectively. Three IROs from three traditional higher education institutions and from urban areas, as well as two DRUs from rural and eight DRUs from urban areas respectively, responded. Six of the responding DRUs belong to traditional institutions, three to institutions of technology, and one to a comprehensive institution.

\section{Data Analysis, Findings and Discussion}

During the data analysis process, four main themes were identified, namely: a) policies, b) statistical data, c) institutional structure, and d) support of international students with disabilities. The last theme consisted of six sub-themes, namely: 1) the pre-departure, 2) study and 3) return phases, 4) the support services and 5) roleplayers, as well as 6) the challenges faced by the incoming and outgoing international students with disabilities. The themes and sub-themes should be viewed within the broader framework of the internationalisation of higher education institutions, which has an important and meaningful influence on the international mobility of students with disabilities.

\subsection{Policies}

The data indicated that currently South Africa does not have an explicit national strategy for the internationalisation of students with disabilities in higher education. Although institutional policies on internationalisation of students are in place at the respondent IROs, there are no specific references to international students with disabilities. It seems that they are included as part of the broader category of international students. However, it is important that reference should be made to their specific learning and access needs. Seven of the respondent DRUs indicated the existence of a policy on the support of international students with disabilities, whereas three respondents pointed out that support of these students was included in the main policy on support of local students with disabilities.

All the respondent institutions have internationalisation strategies in place which promote international ties with institutions abroad, including opportunities for professional staff and student development. However, no clear reference is made to staff and students with disabilities.

\subsection{Statistical Data: International Students with Disabilities}

The lack of accurate and reliable statistical data on international students with disabilities, both at the national and institutional levels in South Africa, was one of the main findings of the research. Although most of the respondent IROs were able to provide statistical data on current international students without disabilities, the information on outgoing and incoming international students with disabilities was inadequate. However, in one instance, the IRO, who works closely together with the DRU at the institution, was able to provide clear data. The lack of statistical data could be the result of the protection of data of personal nature, unwillingness on the part of international students with disabilities to disclose their disability, and insufficient communication between the relevant role-players.

The respondent DRUs, on the other hand, were able to provide statistical data on current students with disabilities. Six DRUs were aware of incoming international students with disabilities, although the number of these students, as captured by the DRUs, was low $(2,3 \%) .{ }^{9}$ Four DRUs indicated that they were not aware of any incoming international students with disabilities. As far as prospective outgoing students with disabilities are concerned, no respondent had any data.

\subsection{Institutional Structure of Respondent IROs and DRUs}

The data indicated that, although each of the 10 respondent institutions had an IRO, the designation of the of-

\footnotetext{
7 Only 10 institutions, out of a total of 22, responded to the questionnaires that were sent out.

${ }^{8}$ The selection criteria for respondent institutions were the following: a) presence of an International Relations Office (IRO) and/or Disability Rights Unit (DRU); b) a representative variety of institutions, including universities of technology, traditional universities and comprehensive universities; c) urban and rural institutions; d) no institutions established during the last three years; and e) no distance education institutions.

${ }^{9} \mathrm{~A}$ total of 64 incoming international students with disabilities out of a total of 2,750 students with disabilities were on the six DRUs' databases. 45 of these international students were from Africa. Rouhani (2007) points out that most sponsors prefer to send students from the rest of the African continent to South Africa rather than overseas for higher education and training. According to Teferra (2017, p. 244) the reason for this is that since "South Africa has a strong economic and highly developed higher education system compared to other African countries, it has become a destination of choice for most African students and scholars wanting to further their studies and career opportunities".
} 
fices differed between the institutions. This was related to the line-function and location of the IRO within each institutional structure. The designation most commonly used was "International Relations Office", although "International Student Division", "Office of International Affairs" and "International Student Office" were also used in a few cases. Most of these offices report directly to the Deputy Vice Rector of the institution.

The designation "Disability Rights Unit" was used at most of the respondent institutions, although two units preferred the term "Disability Unit". Four of the DRUs function as independent units, but report to the Office of Student Affairs. Six respondent DRUs are part of Student Counselling, which also report to the Office of Student Affairs.

\subsection{Support of International Students with Disabilities}

During the data analysis process, it became clear that support services rendered to international students with disabilities could be grouped into three main phases, namely a pre-departure, study and return phase. The roles and responsibilities of the key support role-players in these phases could also be identified.

\subsubsection{Pre-Departure Phase}

Most of the respondents considered the pre-departure phase as the most important. ${ }^{10}$ Respondent IROs and DRUs indicated that, for awareness and marketing purposes, websites were also available for incoming international and prospective outgoing students with disabilities. However, not all websites were accessible. The respondent IROs indicated that their websites provided information on international study opportunities, the application process and general information regarding their offices. The DRUs' websites focused mainly on specialised support services to all students with disabilities, including international students with disabilities.

Although awareness-raising regarding international exchange programmes was pointed out as one of the important roles of IROs, the data showed that, in practice, students with disabilities usually became aware of these opportunities through other sources like friends, class mates, family members and lecturers. These roleplayers were usually aware of international mobility programmes or had been involved in such programmes themselves. However, it became clear that awarenessraising and marketing initiatives regarding international mobility programmes for international students with disabilities needed more attention at most of the respondent institutions.

Two respondents mentioned that in the past, outgoing prospective students with disabilities used the IRO as a "first desk contact place" for application processes, information on study visas, clearance and immigration re- quirements, as well as financial issues. One DRU also assisted some students with the preparation of examination concession and accommodation documents before their departure to the host institution.

Most of the respondents indicated that only a very small percentage of incoming international students with disabilities personally contacted the IROs or DRUs at the host institution before leaving their home country. In cases where they did so, their administrative needs were attended to, but for their additional needs they were in most instances referred by the IRO to the DRU for advice and support.

The information needed by incoming international students with disabilities were in most cases related to application matters, academic programmes, support services, accessibility of buildings, as well as accessible accommodation (technically referred to as "reasonable accommodation"). Unfortunately, most of these students arrived at host institutions without any pre-departure communication with role-players at the host institution. This resulted in serious adjustment challenges for these students in many cases. The reasons for not contacting the host institution included insufficient information, a lack of awareness-raising and marketing of available support services at home and host institutions, the absence of an exchange agreement between the home and host institutions, a lack of communication between key roleplayers and prospective international students, and the preference of some of these students not to disclose his/her disability.

Two IROs and five DRUs indicated that online welcome guides/international student guides were available for all international students. Unfortunately, most of these guides did not provide any information (for e.g., contact numbers) regarding the learning and access support services that were available to international students with disabilities. It is important that role-players in the international mobility process, such as the home and host IROs, as well as the specialised support services and academic coordinators and academics, provide all the necessary information, advise and support to prospective international students with disabilities in their choices of available host institutions and study programmes (EAIE: ADEC, 2014; Soneson \& Cordano, 2007).

$60 \%$ of the respondents indicated that parents were likely to contact DRUs before their son or daughter arrives at the host institution. In most cases the communication related to the severity level of the student's disability, as well as the necessity of the exchange of important information in this regard. One respondent mentioned that their general preference was to work only with the students "because students are adults", but in the case of students with autism, the parents would be contacted.

It is important that, although pre-departure orientation sessions are the responsibility of IROs and DRUs, other role-players are also included, for e.g., travel agen-

\footnotetext{
10 In this regard it has been pointed out that this phase should start well in advance (EAIE: ADEC, 2014), since it could be time-consuming and needed planning.
} 
cies, visiting international students from the host country/institution, returning international students with disabilities, as well as friends and family members who already visited the host country. During orientation sessions involving the institutional role-players, prospective outgoing international students with disabilities and parents, important and necessary information should be shared. Since most students with disabilities have a fear of the unknown and question their own ability to cope in new environments (Fazekas, 2017), these students, as well as their parents, would benefit from predeparture orientation sessions. The EAIE: ADEC (2014, p. 1) also recommends that prospective outgoing international students "consider going on a preparatory study visit...to get a full picture of what to expect (living, learning, social life, etc.), and to get in touch with staff and other students".

\subsubsection{Study Phase}

Furthermore, the data showed that the IRO's level of involvement with incoming international students with disabilities during the study phase depended on the presence of a DRU on campus. If an efficient DRU was in place, the IRO would strongly rely on the DRU's relevant expertise and the support services rendered to students with disabilities.

Although general support services for local students at the respondent institutions were also available to incoming international students with disabilities, these students encounter additional barriers (Fazekas, 2017; Katz, Soneson, \& Cordano, 2007) that have to be addressed. At most of the respondent institutions, financial support for international students was not included. With regard to personal assistance, there was limited support for incoming international students with disabilities. However, a buddy/peer system was available, which was mostly arranged by the DRU of the host institution. At one institution, a local student organisation, together with the DU, arranged the buddy-support for incoming international students with disabilities. Buddies could play an important role in helping and orientating such students in the new study environment. Unfortunately, no information was provided by the respondents on the general training of buddies and other role-players with respect to the learning and access needs of incoming international students with disabilities.

Regarding the availability of maps of the institution's campus(es) and surrounding areas, the data indicated that at most of the respondent institutions this information was lacking. Three institutions indicated that maps were available online. This could provide important information for incoming international students with disabilities (ESN, 2017). The respondents indicated that DRUs should be the first point of contact in cases where these students required information on learning and access needs. In most cases the DRUs also acted as coordinators of support services for these students, in close co- operation with relevant role-players from academic and non-academic departments.

The process of academic support to international students with disabilities differed slightly between the respondent institutions. Language proficiency was regarded by the respondents as the most important aspect for the inclusion or exclusion of incoming international students at the host institutions and in the new environment. However, the data showed that language requirements for these students differed between institutions, which could influence the teaching and learning experience of incoming international students with disabilities drastically.

Respondent institutions had their own social organisations which supported all students, including international students. Stafford (1984) highlights the importance of external role-players in building friendships and relationships, as well as by providing cultural orientation, in the social inclusion of incoming international students with disabilities. Although physical, academic, social and practical support are very important to these students, the data showed that emotional and mental support could be regarded as the most crucial aspect of a successful international experience.

\subsubsection{Return Phase}

Furthermore, the data showed that prior to the return phase some specific final administrative matters had to be attended to. In this regard, IROs could play a leading role in supporting returning international students with disabilities regarding the required procedures and travel arrangements. Gaw (2000) also draws attention to the reverse culture shock experienced by students returning from studying abroad and emphasises that they need a pre-return orientation session to prepare them emotionally for re-entering their home institution and country. This is due to the fact that experiences at the host institution and country often change the students' perceptions and world view. When back at their home institutions, returning international students with disabilities could contribute to awareness-raising, motivation and orientation sessions regarding international mobility programmes (EAIE: ADEC, 2014). Collaboration between the IRO, other relevant role-players and returning international students with disabilities should not be underestimated. The data showed that prospective outgoing international students preferred listening to the international mobility experiences of peers who have already visited host institutions.

\subsubsection{Support Services}

The data showed that incoming international students with disabilities were usually referred by IROs to DRUs for support services, as well as to Student Counselling and academic faculties, where necessary. Support services to incoming and outgoing international students 
with disabilities, which were identified by the respondents, include the following: accessible living (10), accessible learning environment (10), management of exchange scholarship matters (10), personal assistance (4), buddy/peer support (7), selection of modules and assistance in registration (8), additional language courses (6), specific academic support (10), academic support in and out of class (8), mentoring of international students (2), integrated sports, cultural and social activities (8), clinical services (10), counselling services (10), and transport of students with physical disabilities (6). ${ }^{11} \mathrm{~A}$ high percentage of incoming international students with disabilities personally approached DRUs for support or were informed by friends regarding the latter's support services. Referrals from role-players at home institutions or referral information gained from websites accounted for only $10 \%$ of referrals to DRUs.

Three respondents indicated that they were uncertain about the availability of support services rendered by the DRU at their institution. At some institutions, two or more role-players were responsible for the same support services. ${ }^{12}$ According to the data collected, not all support services were provided to incoming international students with disabilities at all the respondent institutions (for e.g., transport). One respondent indicated that all the support services available to other international students were also available to incoming international students with disabilities. This is in line with the important principle of inclusion.

All incoming international students studying at a host higher education institution need support before and during their stay, even more so in the case of international students with disabilities. These students need the same general support as other international students, which is mostly available at respondent higher education institutions, however, in the case of most international students with disabilities, additional support is needed to enable them to be successfully included in the host institution environment (EAIE: ADEC, 2014; Fazekas, 2017). A holistic approach in supporting these students at host institutions is of the utmost importance, and all key roleplayers should be involved.

\subsubsection{Role-Players}

Respondents identified 28 role-players that are involved in supporting incoming international students with disabilities. These role-players represent both the nonacademic and academic institutional sectors, as reflected in Table $1 .^{13}$

Role-players responsible for specific support services for incoming international students differed between institutions. At eight institutions the IROs were responsible for the management of exchange and mobility schol- arship matters, whereas one institution indicated that their Department of Research, Innovation and Support handled these matters. One institution indicated that exchange scholarship matters were provided through their DRU. One IRO provided useful details about the different role-players in their Office and their responsibilities. This included the Manager, a Senior Administrative Officer (for matriculation exemptions), a Coordinator (for study abroad), an Administrator (for administering loans and scholarships), a Student Life and Finance, Programme Administrator (for study abroad) and a Help Desk Assistant (for clearance to register and with responsibility for student files). The data indicated that support of these students by friends, buddies and parents should also not be underestimated. In addition, private providers (e.g., community leaders, personal assistants, medical services, sponsors and host families), should be involved, if needed.

Role-players should be active in different areas of support, depending on their functions and responsibilities in their specific unit, office, department, organisation or external profession. Communication between role-players in meeting the learning and access needs of international students with disabilities is crucial. Unfortunately, the captured data showed a lack of communication and collaboration between specific role-players, as well as a lack of knowledge regarding the specific needs of incoming and outgoing international students with disabilities. Some role-players relied on other roleplayers to provide support in meeting these students' learning and access needs, such as mentoring. In other cases, more than one role-player regarded the same support service as their responsibility. This lack of collaboration often resulted in double provisions of the same support service.

The data showed that respondent DRUs were wellequipped and knowledgeable to support international students with disabilities, and that they mostly functioned as "umbrella" units in supporting incoming and outgoing international students with disabilities in their learning (academic) as well as access (academic and nonacademic) needs. However, these students often experienced a feeling of exclusion in cases where DRUs took responsibility for all the support services. International students with disabilities could only experience real inclusion when all role-players took responsibility for supporting them in their particular field of expertise, for example, by offering of general orientation sessions, organising social and sports events on campus, etc.

\subsubsection{Challenges}

Most of the respondents were not aware of the challenges facing outgoing students with disabilities. One

\footnotetext{
11 The number of respondent higher education institutions which provided the specific support services are indicated in brackets.

12 At the one respondent institution the Residence Department, Infrastructure Department and Disability Rights Unit worked together to provide accommodation access for incoming international students with disabilities.

13 The designations of key role-players at the respondent institutions often differ. The different designations used are indicated in Table 1 by the forward slash (/) symbol.
} 
Table 1. Role-players that support international students with disabilities at the respondent institutions.

\begin{tabular}{|c|c|}
\hline Role-players & Institutional sector \\
\hline International Relations Office (IRO) & Non-academic \\
\hline Disability Rights Unit (DRU) & Non-academic \\
\hline Admissions/Student Enrolment Centre/Administration & Non-academic \\
\hline Financial Department & Non-academic \\
\hline Infrastructure/Facilities Management & Non-academic \\
\hline Examination Office/Assessment Office/Examination Division & Non-academic \\
\hline Office of Student Affairs /Student Support and Services /Student Development & Non-academic \\
\hline Campus Health and Wellness Centre/Campus Clinic/Student Health & Non-academic \\
\hline Residence Department/ Residential Services /Housing services/Housing and Residence Affairs & Non-academic \\
\hline $\begin{array}{l}\text { Student Counselling/Centre for Student Counselling and Development/Counselling } \\
\text { and Careers Development Unit }\end{array}$ & Non-academic \\
\hline Sports Office/Sport and Recreation Unit & Non-academic \\
\hline Social Justice and Transformation Unit & Non-academic \\
\hline Development and Leadership Unit & Non-academic \\
\hline Student Organisations/Student Representative Councils/House Committees & Non-academic \\
\hline Buddy/Peer Support & Non-academic \\
\hline Transport Services/Public Services & Non-academic \\
\hline Private Providers/Sponsors/Host Families & Non-academic \\
\hline Academic Faculties & Academic \\
\hline Academic International coordinators/Academic International Managers & Academic \\
\hline Lecturers & Academic \\
\hline Centre for Teaching and Learning & Academic \\
\hline Centre for Languages/Language Centre & Academic \\
\hline Department of Research Innovation and Support & Academic \\
\hline Centre for Academic Development & Academic \\
\hline Library Services & Academic \\
\hline Sign Language Interpreters & Academic \\
\hline Academic Assistants & Academic \\
\hline Tutors & Academic \\
\hline
\end{tabular}

respondent remarked that these students were essentially catered for by the IRO, and that the DRU had very little contact with them. The same respondent mentioned that very few incoming international students with disabilities at their institution had "high support" needs. These remarks showed a lack of knowledge and insight into the needs of these students. Another respondent highlighted a few main challenges for these students which included language, financial and transport issues, lack of information and orientation, inaccessible residences/buildings and inaccessible academic material. Another respondent mentioned personal challenges experienced by these students which include adapting to a different climate, cultural differences, changes in eating habits, interpersonal relations and concomitant misunderstandings, as well as academic and health difficulties (see also Fazekas \& Ho, 2014; Fazekas, 2017). In addition, incoming international students with disabilities from Africa sometimes experienced a negative attitude from local students, which could be regarded as a form of xenophobia (Shindondola, 2002). Respondents also mentioned that the lack of in-depth preparation during the pre-departure phase could increase the challenges faced by these students in physical, cultural, political, social, academic, and safety areas. All these challenges could contribute to a feeling of loneliness and homesickness.

In summary, the data showed that the lack of communication and collaboration between role-players at most of the respondent higher education institutions could be regarded as the main barrier in supporting international students with disabilities effectively.

\section{A Proposed Support Services Model for Facilitating the Inclusion of Higher Education Incoming International Students with Disabilities}

The model proposed in this section was developed for structuring the support services for all incoming international students, including students with disabilities, within the broader framework of inclusive higher education. The model entails that all the general support services for international students which are rendered by different role-players, should also be made available and offered to incoming international students with disabilities. However, in cases where the incoming international students with disabilities need support for their learning and access needs, the support services also have to include specific units. The model briefly provides informa- 
tion on the specific roles and responsibilities of the relevant role-players. As will be indicated, it differs in this respect from the traditional view that IROs, among other things, are predominantly responsible for the preparation, reception, welcoming, orientation and inclusion of new incoming international students.

Within the proposed model, the IRO's main function is to develop policies, memoranda of understanding, partnerships and relationships with other international higher education institutions. However, marketing and awareness-raising regarding international exchange opportunities for all students, assistance with application and registration procedures, as well as financial issues, especially for students with disabilities, remains the responsibility of the IRO. The IRO has an administrative role and does not have responsibility for the practical inclusion of incoming international students in the host institution's environment. The practical inclusion of these students is the responsibility of the International Student Support Coordinator (ISSC), who supports these students during their pre-departure, study and return phases. However, when the ISSC needs data regarding incoming and outgoing international students and support with the application process for study permits, visas and the payment of international grants, if applicable, the ISSC will communicate and collaborate with the relevant IRO.

The ISSC forms part of the Office of Student Affairs, which has responsibility for all student affairs matters, including the academic and social inclusion of all international students. The ISSC acts as the key role-player and main coordinator of support services for all international students. As a staff member of the Office of Student Affairs, he/she works on a daily basis with the roleplayers and students as their first point of contact, and acts as coordinator of services that relate to the needs of all international students. During the pre-departure phase, the ISSC contacts prospective incoming and outgoing international students, after receiving information from the relevant IRO. With the support of the ISSC and other relevant role-players, these students are prepared for the study phase at the host university. Welcoming events, welcome guides and orientation sessions for all incoming international students are the responsibility of the ISSC. If incoming international students with disabilities need specific support, they are referred to the relevant role-players by the ISSC. One of the main responsibilities of the ISSC is to promote efficient collaboration and communication between all role-players regarding the holistic support of incoming international students with disabilities. This will ensure that all international student matters, including international students with disabilities, will be coordinated and monitored by the ISSC.

In cases where specific support is needed for incoming international students with disabilities, the DRU functions as the key role-player, and works in collaboration with the ISSC. The DRU is responsible for the specific academic support of these students and also works closely together with academic departments. Specific academic support services usually include the provision of adapted and accessible study material, training in the use of assistive devices, arrangements for examination concessions, as well as the use of peer assistants and sign language interpreters. Together with the academic departments, the DRU monitors the academic development of incoming international students with disabilities and provides learning and access support where necessary. The DRU also has the function to advise the ISSC regarding the access needs of incoming international students with disabilities.

Academic departments need to play an important role in the selection process of prospective incoming and outgoing international students with disabilities during the pre-departure phase. During the study phase, academics are responsible for assisting incoming international students with disabilities in their choice of modules and possibly additional language courses, where necessary, as well as the implementation of adapted teaching and assessment methods. The provision of tutors and academic assistants for incoming international students with disabilities, where needed, are also part of their responsibilities. Relevant departments are assisted by the DRU in supporting these students in the classroom environment.

Non-academic departments include the infrastructure, residence and student counselling departments. In collaboration with the ISSC, they are responsible for ensuring the accessibility of buildings, adapted transport, the provision of accessible accommodation (reasonable accommodation), and the emotional and mental support of incoming international students with disabilities. Furthermore, Student Counselling needs to give guidance regarding coping skills, as well as daily and study challenges, if needed.

Student organisations, sport and culture clubs are responsible, in collaboration with the ISSC, for the social inclusion of incoming international students with disabilities by means of social interaction. This includes exposure to a different culture experience, the provision of buddy support, and the promotion of inclusive sport and culture activities.

External role-players, especially host-families, play an important role in supporting incoming international students with disabilities with regard to their basic daily needs during their adaptation period. Other external role-players, which include community leaders, parents, sponsors and medical services, should also support these students emotionally, financially, physically and socially, when needed. The ISSC acts as coordinator of all these support services. Figure 1 presents a diagram of the proposed support services model.

\section{Limitations of the Study}

Although invitations were sent to 22 higher education institutions in South Africa to participate in the study, 


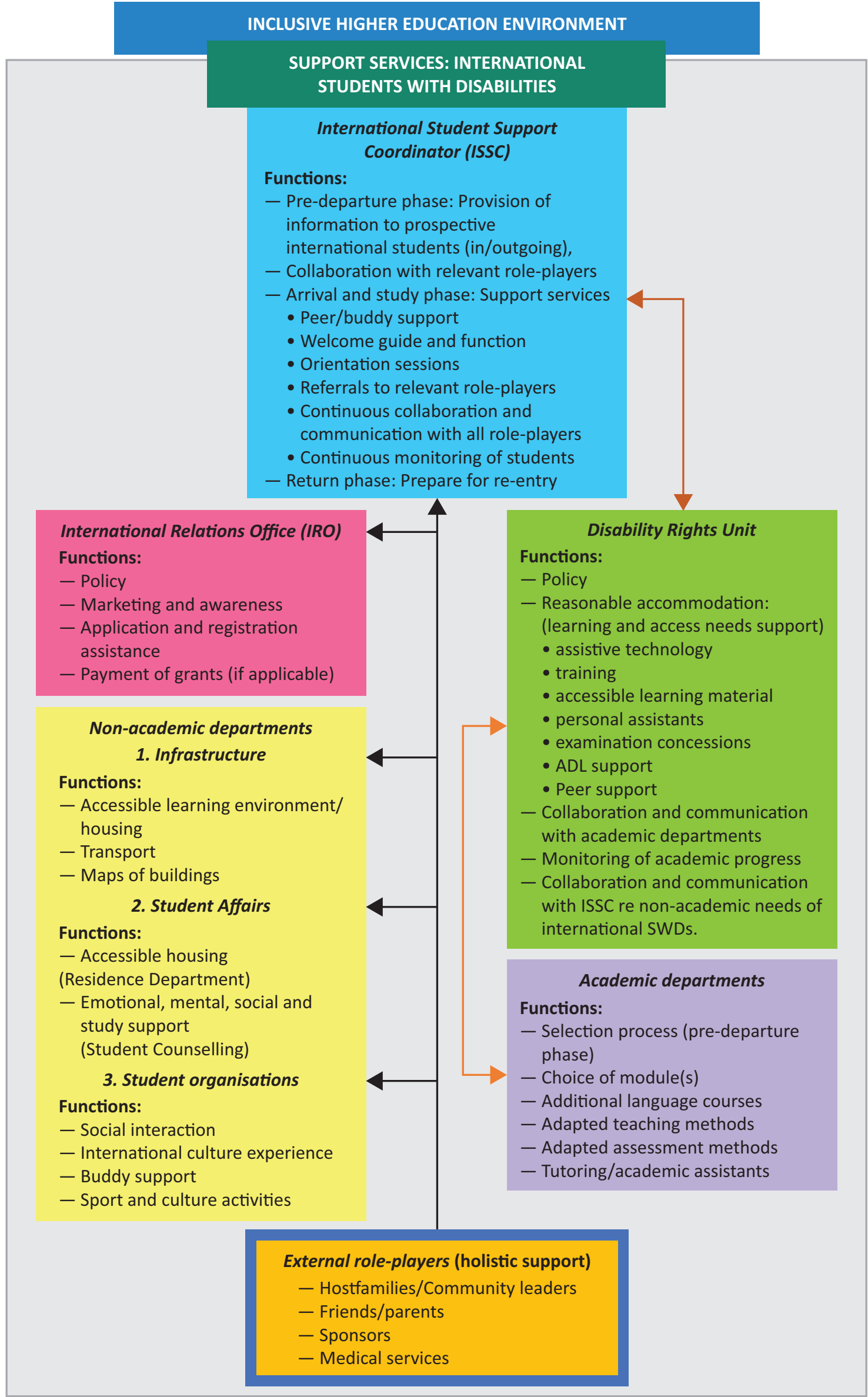

Figure 1. Facilitating the inclusion of higher education incoming international students with disabilities. 
a low percentage of IROs responded. This could be attributed to a number of factors, for example, incorrect contact details and information provided on some websites regarding IROs at higher education institutions, the inability of role-players at higher education institutions to provide the requested information, due to a lack of statistic data on international students with disabilities on campus, protocol policies regarding sharing private information, or difficulties to complete the questionnaires within the time that was available. As a result, the findings have certain limitations, and are not presented as universally applicable.

\section{Recommendations}

Following the findings set out above, the following recommendations are made for facilitating the inclusion of higher education international students with disabilities in South Africa.

\subsection{Investigation and Evaluation}

a) A more comprehensive investigation should be undertaken of the broader framework for, and effect of, internationalisation and international higher education on the human rights of students with disabilities in South Africa. This should include the experiences of outgoing and incoming international students with disabilities;

b) The current institutional structures for the support of international students with disabilities should be evaluated.

\subsection{Awareness-Raising and Marketing}

a) More attention should be given to awareness-raising and the marketing of international exchange opportunities for students with disabilities which highlights the benefits of participating in such programmes;

b) Training and workshops should be offered to key role-players, as well as to the general student population, on the learning and access needs of international students with disabilities, and the challenges that they experience in a disabling environment;

c) An effective online network of international alumni should be created and maintained to support prospective and current international students with disabilities;

d) In cases where international study opportunities are not available, the principle of internationalisation at home (Beelen \& Jones, 2015; EAIE: ADEC, 2014) should be promoted.

\subsection{Role-Players}

a) Role-players, both at the national and institutional levels, should be requested to prioritise the collection of accurate and reliable statistical data on students with disabilities and international students with disabilities by means of efficient data collection tools; b) Dedicated collaboration and open communication between all the relevant role-players at home and at the host institutions are of the utmost importance. Regular interactions, which include meetings and workshops, could contribute in this regard;

c) Joint initiatives should be undertaken by key roleplayers to develop procedures for the support and referral of international students with disabilities to the appropriate role-players;

d) The roles and responsibilities of all relevant roleplayers should be clarified and implemented;

e) A dedicated role-player, namely the ISSC, should coordinate and monitor the support services rendered to all international students in an inclusive environment. This should take place in close cooperation with all the relevant role-players;

f) The national government has an obligation to financially support outgoing international students with disabilities, where necessary.

\subsection{Social Inclusion of International Students with Disabilities}

a) Opportunities for interaction between international students with disabilities and the student population at the host institution should be created at the beginning of the study phase;

b) Open contact groups and workshops could enable international students with disabilities to share their academic experiences with other students and create opportunities for extra support and help;

c) Community partners, for example host families, could contribute to the social and emotional support of international students with disabilities.

\section{Conclusion}

The scarcity, and sometimes lack, of accurate and reliable statistical data on international students with disabilities, both at the national and higher education institution levels in South Africa, was one of the main findings of the research. This could be due to a number factors, for example, the protection of data of a personal nature, unwillingness on the part of the students themselves to disclose their disability, or insufficient communication and sharing of relevant information between the role-players in this area. This points to the need for a comprehensive, accurate, and up to date data-bank on international students with disabilities in higher education, for purposes of future strategic planning, awarenessraising, and meeting the learning and access needs of these students.

Although policies on the internationalisation of students in general are in place at some higher education institutions, there is no specific reference to international students with disabilities. From a human rights' perspective, reference should be made to their specific learning and access needs. This would not only contribute to an 
awareness of these students in the institutional and public spheres, but also to insight and knowledge regarding their access needs.

The low engagement of students with disabilities in international mobility programmes could be ascribed mainly to insufficient awareness and marketing initiatives, among them and the institution at large, regarding the programmes. Other factors, such as fear of the unknown, inaccessible environments and financial constraints could contribute to this. The low engagement issue needs to be addressed to a much greater extent at most of the respondent institutions.

The data showed that DRUs were regarded by the respondent institutions as the main, and sometimes the only, role-player in supporting international students with disabilities during their crucial pre-departure, as well as study and return phases. However, this could contribute to the feeling of exclusion which is often experienced by these students. In this regard the appointment of a dedicated ISSC, who is located specifically in the Office of Student Affairs and works closely in cooperation with all role-players in different departments/units, is crucial for supporting international students with disabilities. This will assure an inclusive environment for these students.

The support roles and responsibilities of other key role-players, such as the IRO, DRU, academic and nonacademic departments and external role-players, should be outlined more clearly than is the case at present, and should be redefined, where necessary, to promote efficiency and prevent the current overlap of functions. The support services model, which was developed during this study, offers several new perspectives on the support roles and responsibilities of the key role-players, and could contribute in this regard.

Finally, the study identified a lack of sufficient knowledge and insight amongst key role-players regarding the specific learning and access needs of incoming international students with disabilities. This is crucial for the success of all support efforts. Awareness-raising and training workshops on general disability issues would benefit all the role-players involved.

\section{Acknowledgements}

This article is part of an Erasmus Mundus INSPIRE project on International Students with Disabilities in Higher Education. The author would also like to thank Prof Dr Geert van Hove for his insightful comments during the project.

\section{Conflict of Interests}

The author declares no conflict of interests.

\section{References}

Altbach, P. G. (2002). Perspectives on international higher education. Change: The Magazine of Higher
Learning, 34(3), 29-31.

Beelen, J., \& Jones, E. (2015). Redefining internationalisation at home. In A. Curaj, L. Matei, R. Pricopie, J. Salmi, \& P. Scott (Eds.), The European higher education area. Between critical reflections and future policies (pp. 59-72). Cham: Springer.

Brademas, J., Fulbright, H. M., \& Sygall, S. (1997). New initiatives. Journal of Studies in International Education, 1(2), 125-131.

Broderick, A. (2018). Equality of what? The capability approach and the right to education for persons with disabilities. Social Inclusion, 6(1), 29-39.

Bronfenbrenner, U. (1979). The ecology of human development: Experiments by nature and design. Cambridge, MA: Harvard University Press.

Cross, M., Mhlanga, E., \& Ojo, E. (2011). Emerging concept of internationalisation in South African higher education: conversations on local and global exposure at the university of the Witwatersrand (Wits). Journal of Studies in International Education, 15(1), 75-92.

Daly, A. J., \& Barker, M. C. (2005). Australian and New Zealand university students' participation in international exchange programs. Journal of Studies in International Education, 9(1), 26-41.

Dean, K. W., \& Jendzurski, M. B. (2013). Using poststudy-abroad experiences to enhance international study. West Chester, PA: West Chester University of Pennsylvania.

Department of Education. (1997). Education white paper 3: A program for the transformation of higher education. Pretoria: DOE.

Department of Higher Education. (2001). National plan for higher education. Retrieved from http://www. justice.gov.za/commissions/FeesHET/docs/2001-Na tionalPlanForHigherEducation.pdf

Department of Higher Education and Training. (2013). White paper on post-school education and training. Building and expanded, effective and integrated postschool system. Pretoria: DHET.

Department of Social Development. (2015). White paper on the rights of persons with disabilities. Pretoria: DSD.

Dessoff, A. (2006). Who is not going abroad? International Educator. Retrieved from https://www.nafsa. org/Resource_Library_Assets/Publications_Library/ Who_s_NOT_Going_Abroad_

De Wit, H. (2011). Trends, issues and challenges in internationalisation of higher education. Amsterdam: Centre for Applied Research on Economics and Management, Hogeschool van Amsterdam.

Edwards, J. J. (2007). Challenges and opportunities for the internationalization of higher education in the coming decade: Planned and opportunistic initiatives in American institutions. Journal of Studies in International Education, 11(3/4), 373-381.

Egron-Polak, E., \& Hudson, R. (2014). Internationalization of higher education: Growing expectations, fun- 
damental values. Paris: IAU.

Erasmus Student Network. (2017). MappED! The platform for inclusive academic mobility. Retrieved from https://www.esn.org/news/mapped-inclusivemobility

European Action on Disability within Higher Education. (2016). The EDGE Project. Retrieved from http://www.eadhe.eu

European Association on International Education: Access and Diversity Expert Community. (2014). The ABC guide to inclusive international mobility for all. Retrieved from https://www.eaie.org/our-resources/ library/publication/Templates/abc-guide-inclusiveinternational-mobility.html

European Commission. (2014). Data collection. Retrieved from http://ec.europa.eu/dgs/education culture/repository/education/library/statistics/ay-12 -13/facts-figures_en.pdf

Fazekas, A. S. (2017). Towards a more inclusive international mobility across Europe. London: Think Pieces GAPS-Education.

Fazekas, A. S., \& Ho, K. (2014). Fostering mobility of students with disabilities in Erasmus Programme. Dublin: AHEAD Educational Press. Retrieved from www.ahead.ie/userfiles/files/Conference/2014/Into \%20the\%20Real\%20World.pdf

Gaw, K. (2000). Reverse culture shock in students returning from overseas. International Journal of Intercultural Relations, 24(1), 83-104.

Holben, A., \& Ozel, C. (2015). International exchange with a disability: Enhancing experiences abroad through advising and mentoring. Journal of Postsecondary Education and Disability, 28(4), 405-412.

Howell, C. (2005). South Africa higher education responses to students with disabilities. Equity of access and opportunity? (Higher Education Monitor no 23). Pretoria: The Council on Higher Education.

Institution of Higher Education. (2016). Students with disabilities, 2006/07-2014/15: Open doors report on international educational exchange. Retrieved from http://www.iie.org/opendoors

International Association of Universities. (2012). Affirming academic values in internationalization of higher education: A call for action. Paris: UAI.

International Association of Universities. (2014). 4th global survey, internationalization of higher education: growing expectations, fundamental values. Retrieved from http://www.iau-aiu.net/sites/all/files /IAU-4th-GLOBAL-SURVEY-EXECUTIVE-SUMMARY.pdf

International Education Association of South Africa. (2014). Nelson Mandela Bay global dialogue. Declaration on the future of internationalisation of higher education. Port Elizabeth, South Africa: EASA.

Katz, E., Soneson, H. M., \& Cordano, R. J. (2007). Students with disabilities studying abroad. International Educator, 16(5), 52-57.

Knight, J. (2004). Internationalization remodelled: Definition, approaches, and rationales. Journal of Studies in International Education, 8(1), 5-31. doi:10.1177/ 1028315303260832

Knight, J. (2013). The changing landscape of higher education internationalisation-For better or worse? Perspectives: Policy and Practice in Higher Education, 17(3), 84-90.

Lutabingwa, J. L. (2005). Internationalisation at South African universities: The role of a central international office. South African Journal of Higher Education, 19(6), 1108-1119.

MacGregor, K. (2014). Major survey of international students in South Africa. University World News South Africa. Retrieved from http://www.university worldnews.com/article.php?story $=20140905134914$ 811

Mavhungu, K. (2003). Internationalisation of a South African university within the African continent: The case of Stellenbosch University. Paper presented at the 7th International Conference of the International Education Association of South Africa (EASA), NorthWest University, Potchefstroom.

McLellan, C. E. (2008). Speaking of internationalisation: An analysis policy of discourses on internationalisation of higher education in post-apartheid South Africa. Journal of Studies in International Education, 12(2), 131-147.

Mitchell, D. E., \& Nielsen, S. Y. (2012). Internationalization and globalization in higher education. Retrieved from https://www.intechopen.com/books/ globalization-education-and-management-agendas/ internationalization-and-globalization-in-higher-edu cation

Mitchell, M. C., \& Vandegrift, D. (2014). Student perceptions of internationalization, multiculturalism, and diversity in the business school. Journal of Teaching in International Business, 25(1), 25-43.

Mitra, S. (2006). The capability approach and disability. Journal of disability policy studies, 16(4), 236-247. https://doi.org/10.1177/10442073060160040501

Mobility International USA. (2017). Advancing disability rights and leadership globally. MIUSA. Retrieved from www.miusa.org/history

Mthembu, T. (2004). Creating a niche in internationalisation for (South) African higher education institutions. Journal of Studies in International Education, 8, 282-296.

Organisation for Economic Co-operation and Development. (2011). Inclusion of students with disabilities in tertiary education and employment. Paris: OECD Publishing. Retrieved from http://www.oecd.org/ education/innovation-education/inclusionofstudents withdisabilitiesintertiaryeducationandemployment. htm

Oxford University. (2017). International trends in higher education 2016-2017. Oxford: University of Oxford International Strategy Office. Retrieved from http:// www.ox.ac.uk/sites/files/oxford/trends\%20in\%20glo balisation_WEB.pdf 
Republic of South Africa. (1996). The constitution of South Africa. Retrieved from http://www.justice. gov.za/legislation/constitution/SAConstitution-webeng.pdf

Rouhani, S. (2007). Internationalisation of South African higher education in the post-apartheid era. Journal of Studies in International Education, 11(3/4), 470-485.

Shindondola, H. K. (2002). Xenophobia in South Africa: The views, opinions and experiences of international students at the Rand Afrikaans University (unpublished MA dissertation). Johannesburg: Rand Afrikaans University.

SIHO, \& LINK Network. (2012). (No)Limits on international exchange? International mobility and students with a disability. Retrieved from http://sites. arteveldehogeschool.be/siho/sites/sites.artevelde hogeschool.be.siho/files/no_limits_on_international _exchange_-_international_mobility_and_students_ with_a_disability_0.pdf

Skinner, N. (2012). Bronfenbrenner's ecological systems theory and applications for management. Retrieved from https://www.academia.edu/1779093/ Bronfenbrenner_s_Ecological_Systems_Theory_and _Applications_for_Management

Soneson, H. M., \& Cordano, R. J. (2007). Students with disabilities self-study for advisers. International Educator, 16(5), 52-57. Retrieved from https://www. nafsa.org/_File/_/educationabroad_iesept_oct.pdf

Stafford, T. (1984). The friendship gap: Reaching out across cultures. Downers Grove, IL: Intervarsity Press. Tadaki, M. (2013). How are we doing higher educa- tion internationalisation? University World News, Global Edition. Retrieved from http://www.university worldnews.com/article.php?story $=20130528180050$ 80

Teferra, D. (2017). International academics in Africa: The South African experience. In M. Yudkevich, P. G. Altbach, \& L. E. Rumbley (Eds.), International faculty in higher education: Comparative perspectives on recruitment, integration and impact. New York: Routledge Taylor and Francis Group.

United Nations. (2006). Convention on the rights of persons with disabilities (UNCRPD). Retrieved from www.un.org/disabilities/documents/convention/con voptprot-e.pdf

United Nations Educational, Scientific and Cultural Organisation. (2017). A guide for ensuring inclusion and equity in education. Retrieved from http:// unesdoc.unesco.org/images/0024/002482/248254e. pdf

Van de Water, J., Green, M., \& Koch, K. (2008). International partnerships: Guidelines for colleges and universities. New York: ACE America Council of Education.

Waters, J. L. (2009). Internationalization of education. In Kitchen, R. \& N. Thrift (Eds.), International encyclopaedia of human geography (pp. 404-406). Oxford: Elsevier.

World Health Organization. (2011). World report on disability. Retrieved from http://www.who.int/ disabilities/world_report/2011/en

\section{About the Author}

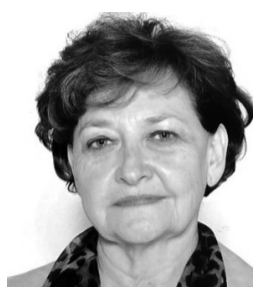

Nina (HG) du Toit (PhD) is a Research Fellow in the Department of Research, Innovation and Partnerships in the Faculty of Informatics and Design at the Cape Peninsula University of Technology, South Africa. She was Head of the Disability Rights Unit at the same university in 2008-2016 and served as vice-chairperson of the South African Higher Education Disability Services Association. Post-doctoral scholarships were awarded to her in 2011 and 2016 for research on disability issues at the Universities of Antwerp and Ghent in Belgium, as part of the Erasmus Mundus programme. 